\title{
PERSPECTIVA SISTÊMICA NOS ARTIGOS PUBLICADOS NOS ANAIS DOS SEMINÁRIOS DA ANPTUR
}

\author{
THE SYSTEMIC PERSPECTIVE IN PAPERS FROM THE ANPTUR SEMINAR PROCEEDINGS
LA PERSPECTIVA SISTÉMICA EN LOS ARTÍCULOS PUBLICADOS EN LOS ANALES DE LOS SEMINARIOS DE LA ANPTUR

Elisângela da Silva Rocha

Professora de Administração/Gestão do Ensino Básico, Técnico e Tecnológico do Instituto Federal Catarinense Campus Camboriú (IFC) - Campus Camboriú Doutoranda em Turismo e Hotelaria na Universidade do Vale do Itajaí (UNIVALI) elisangeladsrocha@gmail.com

Leila A. da Costa

Docente do Curso de Gastronomia. Universidade do Vale do Itajaí (UNIVALI) Doutoranda em Turismo e Hotelaria na Universidade do Vale do Itajaí (UNIVALI) Mestrado em Ciência dos Alimentos - UFSC - Universidade Federal de Santa Catarina leilacosta@univali.br

Francisco Antônio dos Anjos Professor e Pesquisador do Programa de Pós-Graduação em Turismo e Hotelaria - Mestrado e Doutorado na Universidade do Vale do Itajaí (UNIVALI) Doutorado em Engenharia de Produção (Gestão Ambiental) pela Universidade Federal de Santa Catarina (UFSC) anjos@univali.br

Data de Submissão: 04/12/2016 Data de Aceitação: 03/08/2017

RESUMO: A abordagem sistêmica vem sendo difundida na área de turismo como uma das principais vertentes utilizadas como base epistemológica para estudos científicos. A utilização de termos relacionados à abordagem sistêmica foi tema de um estudo desenvolvido por Meira, Conceição e Anjos (2015), por meio de um levantamento dos artigos publicados nos anais do seminário da ANPTUR. Tal levantamento serviu de base para este trabalho, oportunizando uma investigação mais aprofundada. O objetivo do presente estudo foi analisar a coerência da proposta metodológica no que se refere à abordagem sistêmica como eixo condutor do desenvolvimento da pesquisa nos artigos publicados nos anais dos seminários da ANPTUR. A pesquisa é de caráter descritivo, com abordagem quantitativa e qualitativa quanto à análise de conteúdo. Para desenvolver essa análise, foi proposto um quadro com os seguintes níveis de evidência: baixo, parcial e amplo. Para categorizar cada nível, foram estabelecidos critérios que pudessem retratar a real utilização da abordagem sistêmica nos artigos. A contribuição advinda deste estudo está na proposta de estabelecer relações e parâmetros que possibilitem compreender o processo de construção epistemológica e metodológica da pesquisa em turismo - neste caso, na visão da abordagem sistêmica.

PALAVRAS-CHAVE: Turismo. Abordagem sistêmica. Artigos ANPTUR.

ABSTRACT: The systemic approach is being disseminated in the field of tourism as one of the main epistemological bases for scientific studies. Meira, Conceição and Anjos (2015) studied the use of systemic approach-related expressions in papers taken from the proceedings of the ANPTUR seminars. This work used their research as a basis, investigating the issue further. The objective was to analyze the level of coherency of the methodology presented in those papers, in terms of the use of the systemic approach as a foundation for the development of research. This is a descriptive study with a quantitative/qualitative approach, using content analysis. To conduct the analysis, we proposed a table with the following levels of evidence: low, partial and high. We also established criteria that would portray the actual use of the systemic approach in the papers. This study contributes to the area in that it establishes relations and parameters that allow a better understanding of the epistemological and methodological construction of research in tourism - in this case, according to the systemic approach perspective. 
KEYWORDS: Tourism. Systemic approach. ANPTUR papers.

RESUMEN: El abordaje sistémico sigue difundiéndose en el área de turismo como uno de los principales aspectos utilizados como base epistemológica para estudios científicos. La utilización de vocablos relacionados con el enfoque sistémico fue tema de un estudio desarrollado por Meira, Conceição y Anjos (2015) a través de una exploración de los artículos publicados en los anales del seminario de la ANPTUR, que ha servido de base para este trabajo, propiciando una investigación más profunda. El objetivo de este estudio ha sido analizar la coherencia de la propuesta metodológica en lo que se refiere al abordaje sistémico como el hilo conductor del desarrollo de la investigación en los artículos publicados en los anales de los seminarios de la ANPTUR. La investigación es de carácter descriptivo, con abordaje cuantitativo y cualitativo en lo que se refiere al análisis de contenido. Para el desarrollo del análisis se ha propuesto un cuadro con niveles de evidencia: bajo, parcial y amplio. Para la clasificación de cada nivel se han establecido criterios que pudiesen exponer la real utilización del abordaje sistémico en los artículos. La contribución proveniente de este estudio está en la propuesta de establecer relaciones y referencias que posibiliten comprender el proceso de construcción epistemológica y metodológica de la investigación en turismo en este caso, en la visión del abordaje sistémico.

PALABRAS CLAVE: Turismo. Enfoque Sistémico. Artículos ANPTUR.

\section{INTRODUÇÃO}

abordagem sistêmica vem sendo difundida na área de turismo
como uma das principais vertentes utilizadas como base
epistemológica para estudos científicos. Meira, Conceição e Anjos (2015) desenvolveram um estudo sobre a aplicação da abordagem sistêmica no turismo utilizando como referência um levantamento de 558 artigos publicados nos anais do seminário da ANPTUR durante os anos de 2011, 2012, 2013 e 2014. Em continuidade a esse trabalho e diante da necessidade de uma análise mais detalhada dos artigos selecionados, propõe-se um aprofundamento nos estudos, visando caracterizar o uso da perspectiva sistêmica nas pesquisas em turismo no Brasil.

A escolha do seminário é devido ao reconhecimento da representatividade do evento para o retrato da pesquisa científica em turismo no Brasil. A ANPTUR foi fundada em 2002 e congrega docentes e pesquisadores de programas de pós-graduação stricto sensu da área de turismo no país. Conta, em 2017, com os seguintes membros efetivos: Universidade do Vale do Itajaí, Universidade de Caxias do Sul, Universidade Anhembi Morumbi, Universidade de Brasília, Universidade Federal do Paraná, Universidade Federal do Rio Grande do Norte, Universidade Estadual do Ceará, Universidade de São Paulo e Universidade Federal Fluminense (ANPTUR, 2017). 
A presente pesquisa tem caráter descritivo, com abordagem quantitativa, e foi realizada a partir de 70 artigos que usaram a abordagem sistêmica publicados nos anais do seminário da ANPTUR durante os anos de 2011, 2012, 2013 e 2014. Em uma segunda etapa, os artigos identificados foram categorizados em níveis de evidência da abordagem sistêmica. Os artigos que apresentaram um nível amplo foram analisados qualitativamente em relação aos principais autores que nortearam epistemologicamente a abordagem sistêmica.

O presente artigo está estruturado da seguinte forma: uma síntese teórica sobre o tema abordagem sistêmica, procedimentos metodológicos, análise e discussão dos resultados e considerações finais.

\section{ABORDAGEM SISTÊMICA}

Para Bertalanffy (2010), sistema é um conjunto de elementos interdependentes que formam uma totalidade - ou seja, as partes formam o todo. Nesse sentido, Bertalanffy enfatiza a necessidade de a ciência avançar da perspectiva analítica, tão presente no pensamento positivista, para uma perspectiva sistêmica, na qual é impossível estudar as partes isoladamente. Enfim, há uma mudança do pensamento tradicional, que focaliza a análise das partes, para um pensamento sistêmico, que busca entender cada elemento partindo de suas interações para a existência de um "todo" (Ackoff, 1981).

Conforme Alves (2006), a abordagem sistêmica, por meio da Teoria Geral de Sistemas (TGS), oferece uma alternativa diferente da abordagem positivista, que tem se apresentado inadequada para lidar com os diversos tipos de sistemas, pois não consegue envolver sua totalidade. Para Alves, a TGS possui caráter interdisciplinar, multidisciplinar e transdisciplinar e deseja superar a fragmentação do conhecimento e o isolamento científico com o intuito de atender à complexidade do mundo.

Diferente do pensamento positivista, que possui como característica o pensamento reducionista, analítico e mecanicista, o pensamento sistêmico tem caráter expansionista. Considera que o sistema não é focado apenas na decomposição das partes, mas que essas partes precisam estar integradas 
ISSN: 1983-7151

para formar um todo maior, com pensamento sintético, no qual as partes apresentam sua contribuição para o propósito final, que corresponde à teleologia (Ackoff, 1974).

A TGS de Bertalanffy foi constituída a partir dos estudos dos seres vivos. Bertalanffy (2010) constatou que um organismo, para ser entendido, não pode ser encarado como a soma de suas partes - ou seja, o todo é diferente da soma das partes. $\mathrm{Na}$ abordagem sistêmica, o pensamento científico tem por base a perspectiva organicista, racionalista e processual, existindo uma separação clara entre sujeito e objeto - isto é, o pesquisador não interage com o objeto, mas visualiza os elementos pesquisados de forma integrada.

Conforme Bertalanfy (2010), o principal propósito da TGS é a integração nas mais diversas ciências naturais e sociais que se orientam em direção à TGS e que buscam alcançar maior exatidão nos aspectos não físicos da ciência a partir da interdisciplinaridade.

Beaujeu-Garnier (1980) auxilia no entendimento dessa questão quando afirma que o pensamento sistêmico é um método científico que apresenta a vantagem de obrigar a uma formalização rigorosa do raciocínio e de exigir uma metodologia que tenha em conta o caráter interdisciplinar dos fenômenos. Aprimorando os ideais sistêmicos, Capra (2002) propõe o pensar em termos de redes de relações, reforçando a ideia de que a metáfora do conhecimento como um edifício deva ser substituída pela metáfora da rede, pois quando se percebe a realidade como uma rede de relações, as descrições também formam uma rede interconectada de concepções e modelos.

O pensamento sistêmico, de acordo com Capra (2002), é caracterizado por alguns aspectos como a mudança das partes para um todo - ou seja, um sistema surge das relações de organização e das configurações de relações ordenadas, da capacidade de deslocar a atenção entre níveis sistêmicos, é possível encontrar sistemas aninhados dentro de outros sistemas e aplicar os mesmos conceitos a diferentes níveis. Para o pensamento sistêmico, a inversão da relação entre partes e o todo e as propriedades das partes somente podem ser entendidos dentro de um contexto maior, o que envolve explicá-los considerando o seu ambiente. Além disso, a realidade concebida como uma rede de relações implica 
uma mudança epistemológica profunda em relação à concepção tradicional de objetividade científica. Checkland (1981) distingue claramente o termo "pensamento sistêmico" do termo "abordagem sistêmica", afirmando que a abordagem sistêmica utiliza ideias de complexidade para resolver os problemas no mundo real, sem reducionismo, enquanto o pensamento sistêmico usa de conceitos e princípios sistêmicos com base em modelos ou metodologias aplicadas em qualquer área de investigação.

A abordagem sistêmica no turismo é definida por Panosso Netto (2005) como um dos paradigmas dominantes, considerando o turismo como um sistema aberto, em que vários elementos estão interligados e dependentes uns dos outros. Em uma análise mais abrangente da epistemologia do turismo, Panosso Netto (2005) destaca vários autores, como Beni (2001), Leiper (1995), Martinez (2004), Lohmann e Kaim (1999), que utilizaram a teoria sistêmica para a elaboração de modelos estruturais na tentativa de traçar uma estrutura teórica mais coerente para o turismo. Além dos citados, Panosso Netto (2005) apresenta ainda outros autores das fases paradigmática e de transição para novas abordagens: Cuervo (1967), Wahab (1977), Sessa (1982; 1984), Boullon (1983), Krippendorf (1984) e Molina (1991; 1994).

\section{PROCEDIMENTOS METODOLÓGICOS}

A presente pesquisa possui caráter descritivo com abordagem quantitativa e análise comparativa como também qualitativa no que se refere à análise de conteúdo. A fim de atingir o objetivo deste trabalho, realizou-se um levantamento embasado no estudo de Meira, Conceição e Anjos (2015). Foram identificados 59 artigos publicados nos anais da ANPTUR nos anos de 2011, 2012, 2013 e 2014 que utilizaram a abordagem sistêmica.

Em um segundo levantamento, foram identificados 11 novos artigos que apresentavam a abordagem sistêmica. Dessa forma, a presente pesquisa teve como objeto 70 artigos analisados, sendo que, destes, 13 artigos foram publicados nos anais de 2011, 11 artigos eram de 2012, 26 artigos de 2013 e 20 de 2014. 
Para desenvolver este estudo, verificou-se a necessidade de criar elementos que retratassem e servissem de parâmetros para a análise do conteúdo dos artigos em relação ao emprego da abordagem sistêmica como perspectiva científica norteadora dos referidos artigos. Assim, foi proposto um quadro com os seguintes níveis de evidência: amplo, parcial e baixo. Para categorizar cada nível, foram estabelecidos critérios que pudessem retratar a real utilização da abordagem sistêmica.

Quadro 01: Níveis de evidência da abordagem sistêmica nos artigos.

\begin{tabular}{|c|c|}
\hline Baixo & $\begin{array}{l}\text { Sistema é apresentado apenas como conceito; } \\
\text { Apresenta termos que remetem à abordagem sistêmica em única etapa do artigo. }\end{array}$ \\
\hline Parcial & $\begin{array}{c}\text { Apresenta termos que remetem à abordagem sistêmica em mais de uma etapa do artigo; } \\
\text { Apresenta algum esquema, sistema, fluxo ou processo; } \\
\text { Utiliza bases teóricas da abordagem sistêmica; } \\
\text { Explica processo, fluxo ou esquema. }\end{array}$ \\
\hline Amplo & $\begin{array}{c}\text { Os termos que remetem à abordagem sistêmica permeiam todo o artigo, como tema, resumo, } \\
\text { palavras-chave, fundamentação, resultados e considerações finais; } \\
\text { Utiliza bases teóricas da abordagem sistêmica com base nos autores clássicos. }\end{array}$ \\
\hline
\end{tabular}

Fonte: Elaborado pelos autores, 2017.

Em um segundo momento, foi analisado o uso de bases teóricas com referência aos principais autores que sustentam o marco teórico da abordagem sistêmica na perspectiva científica, identificados como os autores clássicos da base epistemológica e os autores da área de turismo, como demonstrado no Quadro 02.

Quadro 02: Principais autores que trabalham com a perspectiva científica da abordagem sistêmica.

\begin{tabular}{|c|c|}
\hline Autores clássicos & $\begin{array}{c}\text { Autores da área de turismo que utilizam a } \\
\text { abordagem sistêmica }\end{array}$ \\
\hline Acerenza, 1987 & Alberto Sessa, 1982 \\
\hline Ackoff, 1981 & Alfonso Martinez, 2004 \\
\hline Beaujeu-Garnier, 1980 & Francisco Dos Anjos, 2004 \\
\hline Buckley, 1971 & Jafar Jafari, 1981 \\
\hline Capra, 1997 & Josildete Oliveira, 2013 \\
\hline Checkland, 1981 & Jost Krippendorf, 1984 \\
\hline Floyd E Carlson, 1988 & Mario Beni, 1988 \\
\hline Ludwig Von Bertalanffy, 1975 & Neil Leiper, 1979 \\
\hline Luhmann, 2009 & Raymundo Cuervo, 1967 \\
\hline Maturana, 1995 & Roberto Boullón, 1985 \\
\hline Morgan, 1996 & Salah-Eldin Abdel Wahab, 1977 \\
\hline Romesín \& Varela Garcia, 1995; 1997 & Sergio Molina, 1991 \\
\hline Varela, 1997 & \\
\hline
\end{tabular}




\begin{tabular}{|c|l|}
\hline Von Foester, 1963 & \\
\hline Wiener, 1948 & \\
\hline
\end{tabular}

Fonte: Elaborado pelos autores, 2017.

\section{ANÁLISE E DISCUSSÃO DOS RESULTADOS}

O presente estudo teve como objetivo analisar a coerência da proposta metodológica no tocante à abordagem sistêmica como eixo condutor do desenvolvimento da pesquisa.

De acordo com os dados extraídos do Quadro 03, o ano de 2011 apresentou um total de 13 artigos, dos quais oito são classificados como nível baixo, representando 61,54\%; três artigos como nível parcial, o que corresponde a 23\%; e dois artigos como nível amplo, o equivalente a 15,38\% do total de artigos de 2011.

Quadro 03: Classificação de artigos da ANPTUR 2011 quanto ao nível de evidência de utilização da abordagem sistêmica.

\begin{tabular}{|c|c|c|c|c|c|c|c|c|}
\hline \multirow{2}{*}{$\begin{array}{c}\text { Níveis } \\
\end{array}$} & \multicolumn{2}{|c|}{ Baixo } & \multicolumn{4}{|c|}{ Parcial } & \multicolumn{2}{|c|}{ Amplo } \\
\hline & $\begin{array}{c}\text { Sistema é } \\
\text { apresenta- } \\
\text { do apenas } \\
\text { como } \\
\text { conceito }\end{array}$ & $\begin{array}{c}\text { Apresenta } \\
\text { termos que } \\
\text { remetem à } \\
\text { aborda-gem } \\
\text { sistêmica em } \\
\text { única etapa } \\
\text { do artigo }\end{array}$ & $\begin{array}{c}\text { Apresenta } \\
\text { termos que } \\
\text { remetem à } \\
\text { aborda-gem } \\
\text { sistêmica em } \\
\text { mais de uma } \\
\text { etapa do } \\
\text { artigo }\end{array}$ & $\begin{array}{l}\text { Apresenta } \\
\text { algum } \\
\text { esquema, } \\
\text { sistema, } \\
\text { fluxo ou } \\
\text { processo }\end{array}$ & $\begin{array}{l}\text { Utiliza } \\
\text { bases } \\
\text { teóricas } \\
\text { da abor- } \\
\text { dagem } \\
\text { sistêmica }\end{array}$ & $\begin{array}{c}\text { Explica o } \\
\text { processo/ } \\
\text { fluxo/ } \\
\text { esquema }\end{array}$ & $\begin{array}{l}\text { Os termos } \\
\text { que } \\
\text { remetem à } \\
\text { aborda-gem } \\
\text { sistêmica } \\
\text { permeiam } \\
\text { todo o } \\
\text { artigo }\end{array}$ & $\begin{array}{c}\text { Utiliza } \\
\text { bases } \\
\text { teóricas } \\
\text { da abor- } \\
\text { dagem } \\
\text { sistêmica } \\
\text { com } \\
\text { base nos } \\
\text { autores } \\
\text { clássicos }\end{array}$ \\
\hline 1 & & & $x$ & & $x$ & & $x$ & $X$ \\
\hline 2 & $x$ & & & & & & & \\
\hline 3 & & & $x$ & & $x$ & & & $x$ \\
\hline 4 & & & $x$ & & & & & \\
\hline 5 & $x$ & & & & & & & \\
\hline 6 & $x$ & & & & & & & \\
\hline 7 & & $x$ & & & $x$ & & & \\
\hline 8 & $x$ & $x$ & & & & & & \\
\hline 9 & & & $x$ & & $x$ & & & \\
\hline 10 & $x$ & & & & & & & \\
\hline 11 & $x$ & & & & & & & \\
\hline 12 & $x$ & & & & & & & \\
\hline 13 & $x$ & & & & & & & \\
\hline
\end{tabular}

Fonte: Elaborado pelos autores, 2017. 
Em 2012, foram analisados 11 artigos (Quadro 04). Dentre eles, cinco foram classificados como nível baixo e nível parcial, representando, cada nível, 45,5\%. Apenas um artigo foi classificado como nível amplo, o que corresponde a $9 \%$ do total de artigos analisados.

Quadro 04: Classificação de artigos da ANPTUR 2012 quanto ao nível de evidência de utilização da abordagem sistêmica.

\begin{tabular}{|c|c|c|c|c|c|c|c|c|}
\hline \multirow[b]{2}{*}{$\begin{array}{l}\text { Níveis } \\
\text { Artigos }\end{array}$} & \multicolumn{2}{|c|}{ Baixo } & \multicolumn{4}{|c|}{ Parcial } & \multicolumn{2}{|c|}{ Amplo } \\
\hline & $\begin{array}{c}\text { Sistema é } \\
\text { apresenta- } \\
\text { do apenas } \\
\text { como } \\
\text { conceito }\end{array}$ & $\begin{array}{c}\text { Apresenta } \\
\text { termos que } \\
\text { remetem } \\
\text { à aborda- } \\
\text { gem } \\
\text { sistêmica } \\
\text { em única } \\
\text { etapa do } \\
\text { artigo }\end{array}$ & $\begin{array}{c}\text { Apresenta } \\
\text { termos que } \\
\text { remetem } \\
\text { à aborda- } \\
\text { gem } \\
\text { sistêmica } \\
\text { em mais de } \\
\text { uma etapa } \\
\text { do artigo }\end{array}$ & $\begin{array}{l}\text { Apresenta } \\
\text { algum } \\
\text { esquema, } \\
\text { sistema, } \\
\text { fluxo ou } \\
\text { processo }\end{array}$ & $\begin{array}{l}\text { Utiliza } \\
\text { bases } \\
\text { teóricas } \\
\text { da abor- } \\
\text { dagem } \\
\text { sistêmica }\end{array}$ & $\begin{array}{c}\text { Explica o } \\
\text { processo/ } \\
\text { fluxo/ } \\
\text { esquema }\end{array}$ & $\begin{array}{l}\text { Os termos } \\
\text { que } \\
\text { remetem } \\
\text { à aborda- } \\
\text { gem } \\
\text { sistêmica } \\
\text { permeiam } \\
\text { todo o } \\
\text { artigo }\end{array}$ & $\begin{array}{c}\text { Utiliza } \\
\text { bases } \\
\text { teóricas } \\
\text { da abor- } \\
\text { dagem } \\
\text { sistêmica } \\
\text { com } \\
\text { base nos } \\
\text { autores } \\
\text { clássicos }\end{array}$ \\
\hline 1 & & & $x$ & & $x$ & & & \\
\hline 2 & & & $x$ & & $x$ & & & $x$ \\
\hline 3 & $x$ & & & & & & & \\
\hline 4 & & & $x$ & & $x$ & & & \\
\hline 5 & & & $x$ & & $x$ & & & \\
\hline 6 & $x$ & & & & & & & \\
\hline 3 & & & $x$ & & & & & \\
\hline 8 & $x$ & & & & & & & \\
\hline 9 & & & $x$ & & $x$ & & & \\
\hline 10 & $x$ & & & & & & & \\
\hline 11 & $x$ & & & & & & & \\
\hline
\end{tabular}

Fonte: Elaborado pelos autores, 2017.

Como demonstrado no Quadro 05, dos 26 artigos analisados em 2013, seis artigos correspondem ao nível baixo, representando 23\%, 19 correspondem ao nível parcial, representando 73\%, e apenas um artigo se refere ao nível amplo, o que corresponde a somente $3,84 \%$ do total dos artigos.

A maioria dos artigos enquadra-se no nível parcial, sendo que dois deles se encaixam em todos os critérios: apresentam termos que remetem à abordagem sistêmica em mais de uma etapa do artigo, apresentam algum esquema, sistema, fluxo ou processo, utilizam bases teóricas da abordagem sistêmica e ainda explicam o processo/fluxo/esquema. Por outro lado, seis artigos enquadramse em três critérios, cinco em dois critérios e seis em apenas um. 
Destaca-se que o único artigo que utiliza bases teóricas da abordagem sistêmica com base nos autores clássicos trata apenas de uma investigação sobre a produção na área de turismo, isto é, o autor não utiliza a abordagem sistêmica em sua pesquisa.

Quadro 05: Classificação de artigos da ANPTUR 2013 quanto ao nível de evidência de utilização da abordagem sistêmica.

\begin{tabular}{|c|c|c|c|c|c|c|c|c|}
\hline \multirow[b]{2}{*}{$\begin{array}{l}\text { Níveis } \\
\text { Artigos }\end{array}$} & \multicolumn{2}{|c|}{ Baixo } & \multicolumn{4}{|c|}{ Parcial } & \multicolumn{2}{|c|}{ Amplo } \\
\hline & $\begin{array}{c}\text { Sistema é } \\
\text { apresenta- } \\
\text { do apenas } \\
\text { como } \\
\text { conceito }\end{array}$ & $\begin{array}{l}\text { Apresenta } \\
\text { termos } \\
\text { que } \\
\text { remetem } \\
\text { à aborda- } \\
\text { gem } \\
\text { sistêmica } \\
\text { em única } \\
\text { etapa do } \\
\text { artigo }\end{array}$ & $\begin{array}{l}\text { Apresenta } \\
\text { termos } \\
\text { que } \\
\text { remetem } \\
\text { à aborda- } \\
\text { gem } \\
\text { sistêmica } \\
\text { em mais } \\
\text { de uma } \\
\text { etapa do } \\
\text { artigo }\end{array}$ & $\begin{array}{l}\text { Apresenta } \\
\text { algum } \\
\text { esquema, } \\
\text { sistema, } \\
\text { fluxo ou } \\
\text { processo }\end{array}$ & $\begin{array}{c}\text { Utiliza } \\
\text { bases } \\
\text { teóricas } \\
\text { da abor- } \\
\text { dagem } \\
\text { sistêmica }\end{array}$ & $\begin{array}{c}\text { Explica o } \\
\text { processo/ } \\
\text { fluxo/ } \\
\text { esquema }\end{array}$ & $\begin{array}{l}\text { Os termos } \\
\text { que } \\
\text { remetem } \\
\text { à aborda- } \\
\text { gem } \\
\text { sistêmica } \\
\text { permeiam } \\
\text { todo o } \\
\text { artigo }\end{array}$ & $\begin{array}{c}\text { Utiliza } \\
\text { bases } \\
\text { teóricas } \\
\text { da abor- } \\
\text { dagem } \\
\text { sistêmica } \\
\text { com } \\
\text { base nos } \\
\text { autores } \\
\text { clássicos }\end{array}$ \\
\hline 1 & & & & & $x$ & $x$ & & \\
\hline 2 & & & $x$ & $x$ & & $x$ & & \\
\hline 3 & & & $x$ & $x$ & & $x$ & & \\
\hline 4 & $x$ & & & $x$ & & & & \\
\hline 5 & $x$ & & & & & & & \\
\hline 6 & & & $x$ & $x$ & $x$ & & & \\
\hline 7 & $x$ & & & & & & & \\
\hline 8 & $x$ & & $x$ & & $x$ & & & \\
\hline 9 & & & $x$ & & & & & \\
\hline 10 & $x$ & & & & $x$ & & & \\
\hline 11 & & & $x$ & $x$ & $x$ & $x$ & & \\
\hline 12 & $x$ & $x$ & & & $x$ & & & \\
\hline 13 & & & $x$ & $x$ & $x$ & $x$ & & \\
\hline 14 & & & $x$ & $x$ & & $x$ & & \\
\hline 15 & $x$ & $x$ & & $x$ & & $x$ & & \\
\hline 16 & & & $x$ & $x$ & & $x$ & & \\
\hline 17 & $x$ & $x$ & & & & & & \\
\hline 18 & $x$ & & $x$ & & & & & \\
\hline 19 & & $x$ & & $x$ & & $x$ & & \\
\hline 20 & & $x$ & & & & & & \\
\hline 21 & & & $x$ & & & & & $x$ \\
\hline 22 & $x$ & $x$ & & & & & & \\
\hline 23 & $x$ & $x$ & & & & & & \\
\hline 24 & $x$ & $x$ & & & & & & \\
\hline 25 & & $x$ & & $x$ & $x$ & $x$ & & \\
\hline 26 & $x$ & $x$ & & & $x$ & $x$ & & \\
\hline
\end{tabular}

Fonte: Elaborado pelos autores, 2017. 
Dos 20 artigos analisados no ano de 2014, sete correspondem ao nível baixo, no qual o sistema é apenas apresentado como conceito e em uma única etapa, representando 35\%. Em contrapartida, 11 artigos são classificados em nível parcial e representam 55\% dos artigos. Apenas dois correspondem ao nível amplo, o que representa $10 \%$ dos artigos.

Quadro 06: Classificação de artigos da ANPTUR 2014 quanto ao nível de evidência da utilização da abordagem sistêmica.

\begin{tabular}{|c|c|c|c|c|c|c|c|c|}
\hline \multirow[t]{2}{*}{ Níveis } & \multicolumn{2}{|c|}{ Baixo } & \multicolumn{4}{|c|}{ Parcial } & \multicolumn{2}{|c|}{ Amplo } \\
\hline & $\begin{array}{c}\text { Sistema é } \\
\text { apresentado } \\
\text { apenas } \\
\text { como } \\
\text { conceito }\end{array}$ & $\begin{array}{l}\text { Apresenta } \\
\text { termos } \\
\text { que } \\
\text { remetem } \\
\text { à aborda- } \\
\text { gem } \\
\text { sistêmica } \\
\text { em única } \\
\text { etapa do } \\
\text { artigo }\end{array}$ & $\begin{array}{c}\text { Apresenta } \\
\text { termos que } \\
\text { remetem } \\
\text { à aborda- } \\
\text { gem } \\
\text { sistêmica } \\
\text { em mais } \\
\text { de uma } \\
\text { etapa do } \\
\text { artigo }\end{array}$ & $\begin{array}{l}\text { Apresenta } \\
\text { algum } \\
\text { esquema, } \\
\text { sistema, } \\
\text { fluxo ou } \\
\text { processo }\end{array}$ & $\begin{array}{c}\text { Utiliza } \\
\text { bases } \\
\text { teóricas } \\
\text { da abor- } \\
\text { dagem } \\
\text { sistêmica }\end{array}$ & $\begin{array}{c}\text { Explica o } \\
\text { processo/ } \\
\text { fluxo/ } \\
\text { esquema }\end{array}$ & $\begin{array}{l}\text { Os termos } \\
\text { que } \\
\text { remetem } \\
\text { à aborda- } \\
\text { gem } \\
\text { sistêmica } \\
\text { permeiam } \\
\text { todo o } \\
\text { artigo }\end{array}$ & $\begin{array}{c}\text { Utiliza } \\
\text { bases } \\
\text { teóricas } \\
\text { da abor- } \\
\text { dagem } \\
\text { sistêmica } \\
\text { com } \\
\text { base nos } \\
\text { autores } \\
\text { clássicos }\end{array}$ \\
\hline 1 & $x$ & $x$ & & & & & & \\
\hline 2 & & & $x$ & & & & & \\
\hline 3 & $x$ & $x$ & & & & & & \\
\hline 4 & & & $x$ & & & & & \\
\hline 5 & $x$ & $x$ & & & & & & \\
\hline 6 & & & $x$ & & & & & \\
\hline 7 & $x$ & $x$ & & & $x$ & & & \\
\hline 8 & $x$ & $x$ & & & & & & \\
\hline 9 & & & $x$ & & $x$ & & & \\
\hline 10 & $x$ & $x$ & & & $x$ & & & \\
\hline 11 & $x$ & $x$ & & & & & & \\
\hline 12 & $x$ & $x$ & & & & & & \\
\hline 13 & & & $x$ & & $x$ & $X$ & & \\
\hline 14 & & & $x$ & & $x$ & $X$ & & $x$ \\
\hline 15 & & & $x$ & $x$ & $x$ & $X$ & & $x$ \\
\hline 16 & $x$ & $x$ & & & & & & \\
\hline 17 & & & $x$ & & $\mathrm{x}$ & & & \\
\hline 18 & $x$ & $x$ & & & $x$ & & & \\
\hline 19 & $x$ & $x$ & & & $x$ & & & \\
\hline 20 & & $x$ & & $x$ & & & & \\
\hline
\end{tabular}

Fonte: Elaborado pelos autores, 2017.

Os artigos foram organizados na Tabela 02 por ano de publicação, quantidade de artigos identificados e seus respectivos níveis de classificação. No total, há 26 artigos classificados em nível baixo, 38 artigos em nível parcial e apenas seis artigos em nível amplo, o que corresponde a 37\% como nível baixo, 54\% 
como parcial e 9\% como nível amplo. Verifica-se, portanto, que o nível parcial de evidência de utilização da abordagem sistêmica é observado na maioria dos artigos publicados na ANPTUR. Os artigos analisados e representados na Tabela 02 estão relacionados nos apêndices A, B, C e D com seus respectivos títulos.

Tabela 02: Número de artigos da ANPTUR nos anos de 2011, 2012, 2013 e 2014 em relação ao nível de utilização da abordagem sistêmica.

\begin{tabular}{c|c|c|c|c|c}
\hline Níveis de classificação & $\mathbf{2 0 1 1}$ & $\mathbf{2 0 1 2}$ & $\mathbf{2 0 1 3}$ & $\mathbf{2 0 1 4}$ & Total \\
\hline Baixo & 08 & 05 & 06 & 07 & 26 \\
\hline Parcial & 03 & 05 & 19 & 11 & 38 \\
\hline Amplo & 02 & 01 & 01 & 02 & 06 \\
\hline
\end{tabular}

Fonte: Elaborado pelos autores, 2017.

Em uma análise comparativa (Gráfico 01), percebe-se que, a partir de 2012, o perfil foi mantido, apresentando os artigos com nível parcial na sua maioria. Já o nível amplo foi mantido de forma regular: de um a dois artigos em todos os anos analisados. Pode-se destacar, em uma perspectiva evolutiva, os anos de 2013 e 2014 com o número de artigos classificados como nível parcial apresentando-se como maioria.

Gráfico 01: Evolução anual do uso da abordagem sistêmica na ANPTUR.

\section{Evolução do uso Abordagem Sistêmica ANPTUR}
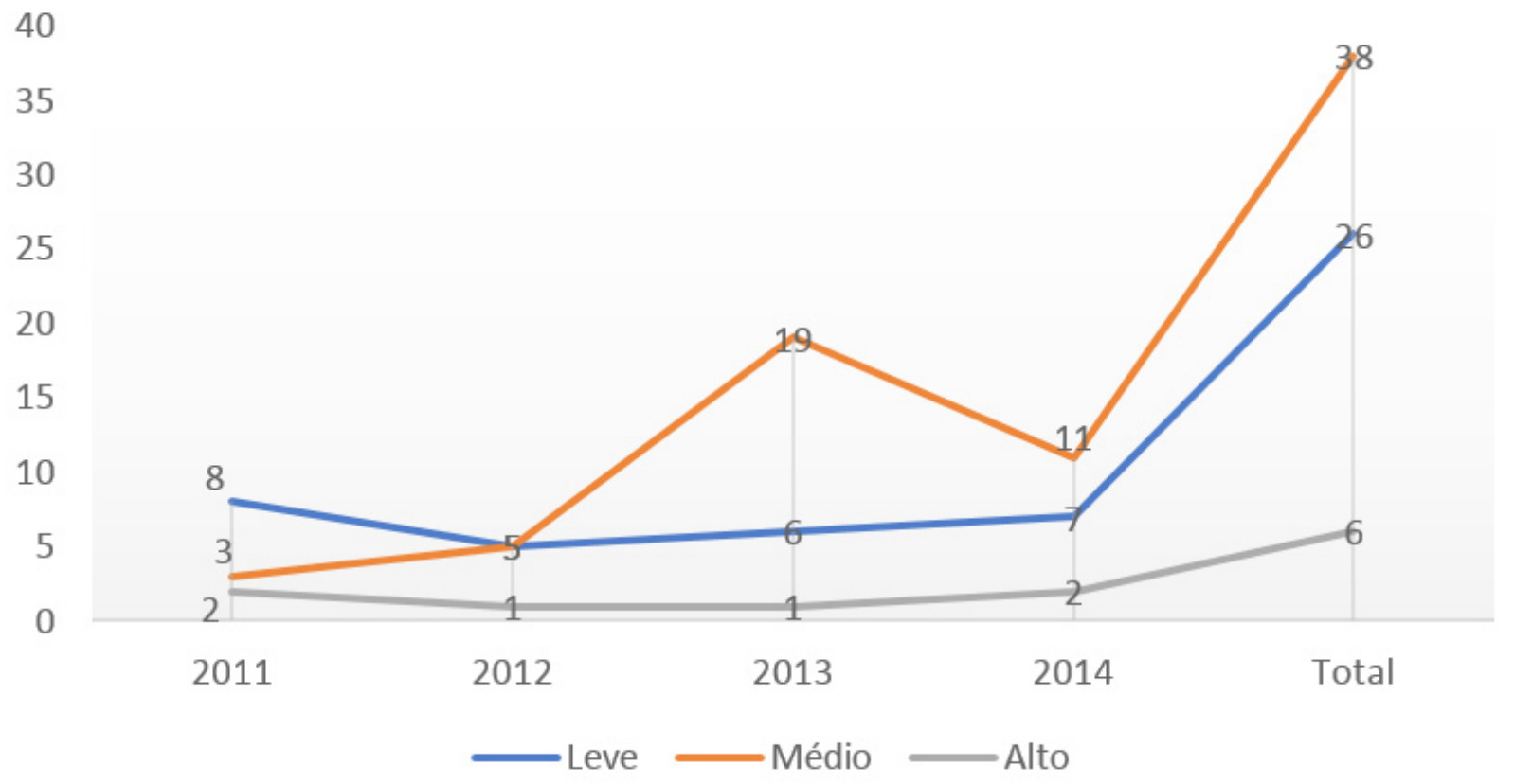

Fonte: Elaborado pelos autores, 2017. 
De acordo com a Divisão Científica da ANPTUR, dos seis artigos que apresentaram níveis amplos, cinco fazem parte do Grupo de Trabalho (GT) de Planejamento do Destino Turístico, e apenas um do GT de Epistemologia e Metodologias da Pesquisa em Turismo.

Para esses mesmos artigos que apresentaram níveis amplos, realizou-se uma análise mais aprofundada no que se refere aos autores que fundamentaram metodologicamente a abordagem sistêmica. Identificou-se claramente a influência da TGS proposta por Bertalanffy (2010) como eixo condutor do desenvolvimento desses artigos.

A teoria sistêmica definida como "autopoiese" foi adotada também como um dos pilares metodológicos em dois artigos. Um deles, relacionado diretamente à Epistemologia e às Metodologias da Pesquisa em Turismo, que já tem como premissa um aprofundamento maior nessas discussões metodológicas, citou Maturana (1997), pesquisador que desenvolveu essa teoria na perspectiva sistêmica. O outro artigo, da área de Planejamento Turístico, teve como referencial norteador Luhmann (2009), para quem os sistemas são dinâmicos tanto pelo seu funcionamento interno como pelas suas relações com o ambiente, gerando operações autoconstitutivas ou autopoiéticas.

Ainda nos artigos que apresentaram um nível amplo, constatou-se a influência de autores como Leiper (1981) e Acerenza (2002), considerando que o sistema turístico é constituído por um conjunto integrado de elementos que se interrelacionam de forma complexa e não linear, o que vem ao encontro com a teoria de Capra (1997) na perspectiva sistêmica de pensar em termos de redes de relações que formam uma rede interconectada de concepções e modelos.

Para as temáticas de Planejamento e Gestão de Turismo, observou-se a adoção da análise sistêmica do turismo de Beni (2006), que considera o sistema de turismo como um conjunto de partes que interagem de modo a atingir um determinado fim, de acordo com um plano ou princípio, incluindo também Martínez (2005) com uma articulação mais aproximada do turismo com a TGS.

Nos artigos voltados para o planejamento estratégico, a abordagem sistêmica fundamentada por Anjos et al. (2005) propõe uma visão integrada e mais completa, que vê o sistema tanto na sua totalidade quanto nas suas 
relações, considerando todos os seus elementos: naturais, humanos, sociais, econômicos, tangíveis e intangíveis, fixos e fluxos, forma e função.

\section{CONSIDERAÇÕES FINAIS}

O presente estudo teve como objetivo analisar a coerência da proposta metodológica no que se refere à abordagem sistêmica como eixo condutor do desenvolvimento da pesquisa. Para desenvolver essa análise, foi proposto um quadro com três níveis de evidência: baixo, parcial e amplo. Para categorizar cada nível, foram estabelecidos critérios que pudessem retratar a real utilização da abordagem sistêmica.

Os níveis de evidência propostos possibilitaram analisar com mais eficiência a utilização da abordagem científica. Relacionando os resultados com os critérios propostos para cada nível, pôde-se constatar que a maioria dos artigos (54\%) foi classificada como nível parcial, ou seja, apresenta termos e utiliza bases teóricas que remetem à abordagem sistêmica e/ou apresenta e explica algum esquema, sistema, fluxo ou processo.

Os artigos classificados como nível baixo foram identificados em número intermediário (37\%) - em outras palavras, o sistema é retratado apenas como conceito, e esses artigos apresentam termos que remetem à abordagem sistêmica em uma única etapa. Pode-se destacar também, em uma perspectiva evolutiva, os anos de 2013 e 2014 com o número de artigos classificados como nível parcial, apresentando-se como maioria.

Os artigos que foram identificados como níveis amplos representam a minoria (9\%) - ou seja, apresentam termos que remetem à abordagem sistêmica permeando todo o artigo e utilizam bases teóricas da abordagem sistêmica.

Cabe aqui destacar que, dos seis artigos considerados de nível amplo, cinco estão voltados para a área de Planejamento do Destino Turístico, possivelmente pelo fato de a abordagem sistêmica ter caráter interdisciplinar e permitir uma visão mais organizada e dinâmica - condições pertinentes no que diz respeito ao planejamento do turismo. Os autores que fundamentaram metodologicamente a abordagem sistêmica nesses referidos artigos permeiam também os demais 
ISSN: 1983-7151

artigos aqui analisados e são parte integrante e fundamental do marco teórico da abordagem sistêmica na perspectiva científica do turismo.

A contribuição advinda deste estudo está na proposta de estabelecer relações e parâmetros que possibilitem compreender o processo de construção epistemológica e metodológica da pesquisa em turismo - neste caso, na visão da abordagem sistêmica. Consideram-se relevantes novas pesquisas voltadas para os artigos publicados nas revistas nacionais e internacionais, colaborando assim com o conhecimento de novas articulações teóricas e perspectivas metodológicas que contribuam para a evolução científica da área de turismo.

\section{REFERÊNCIAS}

Acerenza, M. A. (2002). Administração do turismo: conceituação e organização. Vol. 1. SP: EDUSC Bauru. Beni, MC (2001). Análise estrutural do turismo, 96-107.

Ackoff, R. L. (1981). Creating the corporate future: plan or be planned for. University of Texas Press.

Alves, J. B. D. M. \& Kern, V. (2006). Teoria geral de sistemas. VI Seminário da Associação Brasileira de Pesquisa e Pós-Graduação em Turismo, São Paulo, SP, Brasil. Recuperado de: http://www.anptur.org.br/ocs/index.php/seminario/2009/paper/view/131/25.pdf

Barcellos, P. F. P., Andrade, A. D. L. \& Nóbrega Filho, A. (2005). Construção do futuro com grupos sociais complexos: utilizando o pensamento sistêmico no planejamento de longo prazo com a participação de comunidades de aprendizagem. Revista de AdministraçãoRAUSP, 40(4), 321-329.

Bertalanffy, L. V. (2010). Teoria geral dos sistemas: fundamentos, desenvolvimento e aplicações. $5^{a}$ edição. Tradução Francisco M. Guimarães. Petrópolis (Rio de Janeiro): Vozes.

Beaujeu-Garnier, J. (1980). O comércio na cidade. Geografia Urbana. Tradução de Raquel Soeiro de Brito. Lisboa: Fundação Calouste Gulbenkian, 203-364.

Capra, F. (1997). A teia da vida: uma nova concepção científica dos sistemas vivos. São Paulo: Cultrix/Amana Key.

Capra, F. (2002). Conexões ocultas: ciência para uma vida sustentável. São Paulo: Cultrix.

Checkland, P. (1981). Systems thinking, Systems practice. Chichester, West Sussex, England: John Wiley \& Sons. 
Meira, J. V. de S., Conceição, C. C. \& Anjos, F. A. (2015). Aplicação da abordagem sistêmica no turismo: uma análise dos artigos publicados nos anais dos seminários da ANPTUR. XII Seminário da Associação Nacional de Pesquisa e Pós-Graduação em Turismo, Natal, RN, Brasil. Recuperado de: http://www.anptur.org.br/anptur/anais/v.11/DFP1_pdf/50.pdf

Leiper, N. (1979). The framework of tourism: towards a definition of tourism, tourist, and the tourist industry. Annals of tourism research, 6(4), 390-407.

Leiper, N. (2008). Towards a cohesive curriculum in tourism: the case for a distinct discipline. 1981.

Luhmann, N. \& Nasser, A. C. A. (2009). Introdução à teoria dos sistemas: aulas publicadas por Javier Torres Nafarrate. Vozes.

Martínez, A. D. J. J. (2005). Aproximação à conceituação do Turismo a partir da Teoria Geral de Sistemas. Análises regionais e globais do turismo brasileiro. São Paulo: Roca.

Maturana, H. R. \& Garcia, F. J. V. (1997). De máquinas e seres vivos: autopoiese; a organização do vivo. Artes médicas.

Maturana, H. \& Varela, F. (1995). A árvore do conhecimento. Campinas: Psy.

Panosso Netto, A. (2005). Filosofia do turismo. Teoria e epistemologia. 2a edição. São Paulo: Aleph.

Apêndice A - Classificação de artigos da ANPTUR 2011 quanto ao nível de evidência de utilização da abordagem sistêmica.

\begin{tabular}{|c|c|}
\hline \multicolumn{2}{|r|}{ Níveis/Classificação 2011} \\
\hline $\mathrm{N}^{\circ}$ & Artigos \\
\hline 1 & $\begin{array}{c}\text { Acessibilidade para pedestres com deficiência em espaços turísticos urbanos: } \\
\text { a situação da área central de Balneário Camboriú (SC) }\end{array}$ \\
\hline 2 & Dialética da apropriação/negação: tentativas de interpretação das relações entre o espaço e o turismo \\
\hline 3 & $\begin{array}{c}\text { Planejamento turístico em Unidades de Conservação Públicas: espeleoturismo no } \\
\text { Parque Estadual Turístico do Amplo Ribeira (PETAR), SP1 }\end{array}$ \\
\hline 4 & $\begin{array}{l}\text { Novas abordagens teórico-metodológicas para o estudo do turismo: um ensaio sobre resiliência } \\
\text { socioecológica na Costa Paraense }\end{array}$ \\
\hline 5 & Corpo coletivo acolhedor: uma proposição teórica \\
\hline 6 & $\begin{array}{l}\text { O ethos do corpo coletivo acolhedor da cidade de Bento Gonçalves: análise do } \\
\text { discurso de apresentação }\end{array}$ \\
\hline 7 & $\begin{array}{l}\text { A sustentabilidade de destinos turísticos expressa no website das localidades: o caso de Fernando } \\
\text { de Noronha }\end{array}$ \\
\hline 8 & Análise SWOT do Projeto de Extensão Comunidade Ativa do Curso de Turismo da UFMA \\
\hline 9 & $\begin{array}{c}\text { Metodologia para estudo de identificação de oportunidades de investimentos para } \\
\text { o setor turismo: uma proposta }\end{array}$ \\
\hline
\end{tabular}




\begin{tabular}{|c|c|}
\hline 10 & O turismo na geografia entre críticas e conceitos. \\
\hline 11 & Marinas no litoral brasileiro: território, interescalaridade e planejamento \\
\hline 12 & O estado atual das pesquisas sobre competitividade turística no Brasil \\
\hline 13 & $\begin{array}{c}\text { A dialética na perspectiva do materialismo histórico: um procedimento epistemológico para a } \\
\text { leitura do turismo em sua essencialidade }\end{array}$ \\
\hline
\end{tabular}

Fonte: Elaborado pelos autores, 2017.

Apêndice B - Classificação de artigos da ANPTUR 2012 quanto ao nível de evidência de utilização da abordagem sistêmica.

\begin{tabular}{|c|c|}
\hline \multicolumn{2}{|c|}{ Níveis/Classificação 2012} \\
\hline$N^{\circ}$ & Artigos \\
\hline 1 & Sistema de governança e o desenvolvimento turístico de Salvador /Bahia \\
\hline 2 & Autopoiese e sistema turístico \\
\hline 3 & Estradas-parque como patrimônio ambiental e com usos turísticos no Brasil \\
\hline 4 & $\begin{array}{c}\text { Transposição das noções operatórias de Bourdieu: habitus, campo, poder simbólico para o estudo } \\
\text { da memória turística do território }\end{array}$ \\
\hline 5 & Turismo e a produção científica sobre transporte aéreo na pós-graduação stricto sensu brasileira \\
\hline 6 & Planejamento urbano e a competitividade de destinos turísticos \\
\hline 3 & Nacional de Turismo \\
\hline 8 & Relacionamento entre organizações e competitividade turística: um estudo sobre o Conselho \\
\hline 9 & Aglomerações territoriais no turismo: uma análise teórica e proposições de pesquisa \\
\hline 10 & $\begin{array}{c}\text { O processo logístico na hotelaria: um estudo comparativo entre dois hotéis localizados na região } \\
\text { Sul do Brasil }\end{array}$ \\
\hline 11 & Gestão de receitas na hotelaria: Revenue Management em Foz do Iguaçu - PR \\
\hline
\end{tabular}

Fonte: Elaborado pelos autores, 2017.

Apêndice C - Classificação de artigos da ANPTUR 2013 quanto ao nível de evidência de utilização da abordagem sistêmica.

\begin{tabular}{|c|c|}
\hline \multicolumn{2}{|r|}{ Níveis/Classificação 2013} \\
\hline No & Artigos \\
\hline 1 & Bom Jesus da Lapa (BA) — "Capital da Fé" e turismo religioso: desafios e possibilidades \\
\hline 2 & Uma discussão teórico-metodológica para a análise das políticas de turismo no Brasil \\
\hline 3 & $\begin{array}{c}\text { A turistificação da zona portuária do Rio de Janeiro: por um turismo situado no } \\
\text { Morro da Conceição, Brasil }\end{array}$ \\
\hline 4 & $\begin{array}{l}\text { Identidade como variável interveniente ao desenvolvimento local: um estudo de caso no distrito } \\
\text { de Lavras Novas }\end{array}$ \\
\hline 5 & Turismo arqueológico no Seridó potiguar: possibilidades e entraves para o desenvolvimento regional \\
\hline 6 & $\begin{array}{c}\text { Releitura técnica do tema Turismo no Parque Tecnológico Itaipu Brasil: uma inovação conceitual } \\
\text { para uma prática inovadora em desenvolvimento territorial }\end{array}$ \\
\hline 7 & Variabilidade climática e turismo: o papel do turismo comunitário para mitigação dos impactos \\
\hline 8 & $\begin{array}{l}\text { A geração de resíduos sólidos aeroportuários: o caso do Aeroporto Hugo Cantergiani, Caxias do } \\
\qquad \text { Sul - RS }\end{array}$ \\
\hline 9 & Gestão ambiental em aeroportos como objeto de estudo nos programas stricto sensu no Brasil \\
\hline 10 & $\begin{array}{l}\text { O turismo de massa em debate: a importância de sua análise para o planejamento turístico do } \\
\text { estado de Alagoas, Brasil }\end{array}$ \\
\hline
\end{tabular}


Dor: 10.14210/rtva.v19n3.p614-631

\begin{tabular}{|c|c|}
\hline 11 & estor Pelotas no planejamento do destino turístico \\
\hline 12 & nistória do turismo no município de Silveira Martins - RS \\
\hline 13 & $\begin{array}{l}\text { Mapeando os modelos de planejamento turístico: em busca de refinamento teórico com vistas à } \\
\text { intervenção qualificada }\end{array}$ \\
\hline 14 & Investimentos e desenvolvimento da competitividade em destinos indutores do turismo brasileiro \\
\hline 15 & Análise do turismo local de Londrina - PR à luz da teoria dos stakeholders \\
\hline 16 & Logística integrada de eventos: um estudo de caso da Fenaoeste de São Borja/RS \\
\hline 17 & Acolhimento e desenvolvimento socioturístico: para uma psicopedagc \\
\hline 18 & A formação socioespacial no contexto da infraestrutura rodoviária volta \\
\hline 19 & Patrimônio cultural e políticas públicas: uma a \\
\hline 20 & O percurso Centro-Borda \\
\hline 21 & $\begin{array}{l}\text { Investig(Ação) e inscriacionice na pesquisa em turismo: desafios na produção das trilhas e 'costura' } \\
\text { metodológica da 'viagem investigativa' }\end{array}$ \\
\hline 22 & $\begin{array}{l}\text { Paradigmas epistemológicos e pedagógicos subjacentes ao conceito de turismo pedagógico: em } \\
\text { busca de uma sistematização teórica }\end{array}$ \\
\hline 23 & Contribuições da pós-graduação stricto sensu para o desenvolvimento sustentável: Brasil 1998-2013 \\
\hline 24 & Análise da criatividade e inovação dos city tours em Curitiba desde a perspectiva experencial e emocional \\
\hline 25 & $\begin{array}{l}\text { Estudos de competitividade turística - comparativo do modelo de Dwyer e Kim e o estudo de } \\
\text { competitividade dos } 65 \text { destinos indutores }\end{array}$ \\
\hline 26 & A urbanização turística de Gramado (RS): considerações iniciais de sua apropriação espacial \\
\hline
\end{tabular}

Fonte: Elaborado pelos autores, 2017.

Apêndice D - Classificação de artigos da ANPTUR 2014 quanto ao nível de evidência de utilização da abordagem sistêmica.

\begin{tabular}{|c|c|}
\hline \multicolumn{2}{|r|}{ Níveis/Classificação 2014} \\
\hline $\mathrm{N}^{\circ}$ & Artigos \\
\hline 1 & Profissionais de turismo nos museus: por quê? Para quê? \\
\hline 2 & Revisitando o espaço turístico a partir da multiescalaridade territorial \\
\hline 3 & $\begin{array}{c}\text { A experiência da formação e da atuação do curso técnico em Turismo e Entretenimento do Centro } \\
\text { Federal e Educação Tecnológica Celso Suckow da Fonseca no Rio de Janeiro/RJ, Brasil }\end{array}$ \\
\hline 4 & Influência do contexto sócio-histórico-cultural na qualidade do acolhimento turístico \\
\hline 5 & $\begin{array}{l}\text { Estratégias de comunicação e informação turística: análise dos materiais promocionais de Curitiba/ } \\
\qquad \text { PR no período pré-copa FIFA } 2014\end{array}$ \\
\hline 6 & $\begin{array}{c}\text { Percepção ética dos estudantes diante de dilemas de cunho social, econômico e ambiental } \\
\text { concernentes à atividade turística }\end{array}$ \\
\hline 7 & Percepções turísticas: como a comunidade local representa e simboliza o destino Foz do Iguaçu - PR? \\
\hline 8 & Estratégia empresarial em períodos de crise: um estudo do setor hoteleiro de Belo Horizonte \\
\hline 9 & $\begin{array}{l}\text { Observatório do Turismo de Paranaguá: uma ferramenta de monitoramento e gestão estratégica } \\
\text { do destino }\end{array}$ \\
\hline 10 & $\begin{array}{c}\text { A Política Nacional de Turismo da Venezuela: perspectivas para um desenvolvimento turístico } \\
\text { contra-hegemônico }\end{array}$ \\
\hline 11 & $\begin{array}{c}\text { Gestão participativa e o desenvolvimento sustentável do turismo: reflexões sobre o funcionamento } \\
\text { do Fórum da Região dos Negócios em Goiás }\end{array}$ \\
\hline 12 & $\begin{array}{c}\text { Governança na regionalização do turismo: uma análise exploratória da região turística do litoral do } \\
\text { Paraná/Brasil }\end{array}$ \\
\hline 13 & $\begin{array}{c}\text { O Plano Estratégico Turístico da praia de Barra Grande - Piauí (PI) / Brasil: melhorias a partir da } \\
\text { análise de um modelo sistêmico }\end{array}$ \\
\hline
\end{tabular}




\begin{tabular}{|c|c|}
\hline 14 & $\begin{array}{c}\text { O sistema territorial turístico: uma análise sob a ótica do planejamento estratégico do município } \\
\text { de Joinville }\end{array}$ \\
\hline 15 & $\begin{array}{r}\text { Planejamento, paisagem urbana e turismo: uma análise da paisagem urbana de Bonito, MS, a } \\
\text { partir da proposta de Vicente Del Rio }\end{array}$ \\
\hline 16 & $\begin{array}{c}\text { 'Projecto Querença': redes e parcerias como base para o desenvolvimento local e um turismo rural } \\
\text { na Aldeia de Querença - Portugal }\end{array}$ \\
\hline 17 & $\begin{array}{c}\text { A valorização dos vizinhos: obstáculos para a inclusão socioprodutiva de pescadores artesanais e } \\
\text { agricultores familiares em destinos turísticos brasileiros }\end{array}$ \\
\hline 18 & $\begin{array}{c}\text { Mãos que ajudam o desenvolvimento local através do turismo: o caso da Cocada na Kenga, em } \\
\text { Lucena - PB }\end{array}$ \\
\hline 19 & Competitividade, inovação e desenvolvimento de destinos turísticos: uma perspectiva transversal \\
\hline 20 & Dança: possibilidades e aceitação como produto turístico \\
\hline
\end{tabular}

Fonte: Elaborado pelos autores, 2017.

\section{CONTRIBUIÇÃO DOS AUTORES NA CONSTRUÇÃO DO ARTIGO}

ROCHA: Pesquisa bibliográfica para fundamentação teórica; Levantamento artigos publicados nos anais dos seminários da Anptur; Criação de parâmetros para a análise do conteúdo dos artigos em relação ao emprego da abordagem sistêmica como perspectiva científica norteadora dos referidos artigos; Análise e categorização da abordagem sistêmica nos artigos publicados nos anais dos seminários da Anptur; Formatação do artigo com base nas diretrizes da revista Turismo, Visão e Ação; Correções conforme sugestão dos avaliadores da revista Turismo, Visão e Ação.

COSTA: Pesquisa bibliográfica para fundamentação teórica; Levantamento artigos publicados nos anais dos seminários da Anptur; Criação de parâmetros para a análise do conteúdo dos artigos em relação ao emprego da abordagem sistêmica como perspectiva científica norteadora dos referidos artigos; Análise e categorização da abordagem sistêmica nos artigos publicados nos anais dos seminários da Anptur; Formatação do artigo com base nas diretrizes da revista Turismo, Visão e Ação; Correções conforme sugestão dos avaliadores da revista Turismo, Visão e Ação.

ANJOS: Orientação do conteúdo e discussão dos resultados; Correção do artigo; Revisão do artigo conforme sugestão dos avaliadores da revista Turismo, Visão e Ação. 